Research Article

\title{
Energy Dissipation Characteristic of Red Sandstone in the Dynamic Brazilian Disc Test with SHPB Setup
}

\author{
Fengqiang Gong ${ }^{10}{ }^{1,2}$ and Jian $\mathrm{Hu}^{1}$ \\ ${ }^{1}$ School of Resources and Safety Engineering, Central South University, Changsha 410083, China \\ ${ }^{2}$ School of Civil Engineering, Southeast University, Nanjing 211189, China \\ Correspondence should be addressed to Fengqiang Gong; fengqiangg@126.com
}

Received 3 December 2019; Accepted 20 February 2020; Published 22 April 2020

Academic Editor: Arnaud Perrot

Copyright (c) 2020 Fengqiang Gong and Jian Hu. This is an open access article distributed under the Creative Commons Attribution License, which permits unrestricted use, distribution, and reproduction in any medium, provided the original work is properly cited.

\begin{abstract}
In order to quantitatively investigate the energy dissipation characteristic during the dynamic tension failure of rock materials, the dynamic Brazilian disc tests on red sandstone were conducted using the split Hopkinson pressure bar (SHPB) setup. The states of the specimens after different incident energies can be divided into three forms (i.e., the unruptured state, the ruptured state, and the broken state), and the failure processes of the specimens were recorded by using a high-speed camera. The results show that the ruptured state of the specimen corresponds to the critical failure strain. Taking the critical incident energy as a turning point, two positive linear fitting relations between the dissipated energy and incident energy before and after the point are obtained, and the dynamic linear dissipation law is found. When the incident energy is less than the critical energy, specimens were unruptured after impact. When the incident energy is greater than the critical energy, specimens will be broken after impact. According to the obtained linear energy dissipation law, the dynamic tensile energy dissipation coefficient (DTEDC) was introduced for quantitatively describing the dynamic energy dissipation capacity of rock materials in the dynamic Brazilian disc test. When the specimen is in the unruptured state, the ideal DTEDC is a constant value. When the specimen is in a broken state, the DTEDC increases with the increase of incident energy.
\end{abstract}

\section{Introduction}

The tensile property is one of the mechanical properties of rock materials. Many rock engineering failures are often caused by local or global tension stress. Currently, the Brazilian disc test is a commonly used indirect tensile test method recommended by many experimental procedures [1-5]. On the other hand, rock materials are often subjected to dynamic loads, such as impact, blasting, and vibration, and the Split Hopkinson pressure bar (SHPB) has become a common device used for studying the dynamic failure of rocks under high loading rates or strain rate. [3, 6-9] The study of dynamic tensile properties of rock materials by using the Brazilian disc test has attracted many researchers' attention. Gong and Zhao [6] put forward a DIF (dynamic increase factor) model to describe the dynamic tensile properties of sandstone in the range of low loading rate to the high loading rate. Asprone et al. [10] investigated the dynamic behavior of a Mediterranean natural stone in dynamic direct tensile tests. Wang et al. [11] suggested that the Flattened Brazilian Disc specimen could be used in the dynamic tensile test of rock. Cadoni [12] reported the dynamic tensile characteristics of Orthogneiss rock in the range of intermediate to high strain rates. Dai and Xia [13] conducted dynamic Brazilian disc tests on Barre granite and confirmed the dependence between the tensile strength and loading rate. Wu et al. [14] carried out the dynamic tensile tests of rock under the hydrostatic confinement.

The above research is more focused on the rate effect of rock tensile strength by numerical simulation or laboratory test, but less from the perspective of energy consumption. In fact, the absorption and transformation of energy is the essential cause of rock material failure. [15-18]. Especially in the dynamic test, the incident energy carried by the incident 

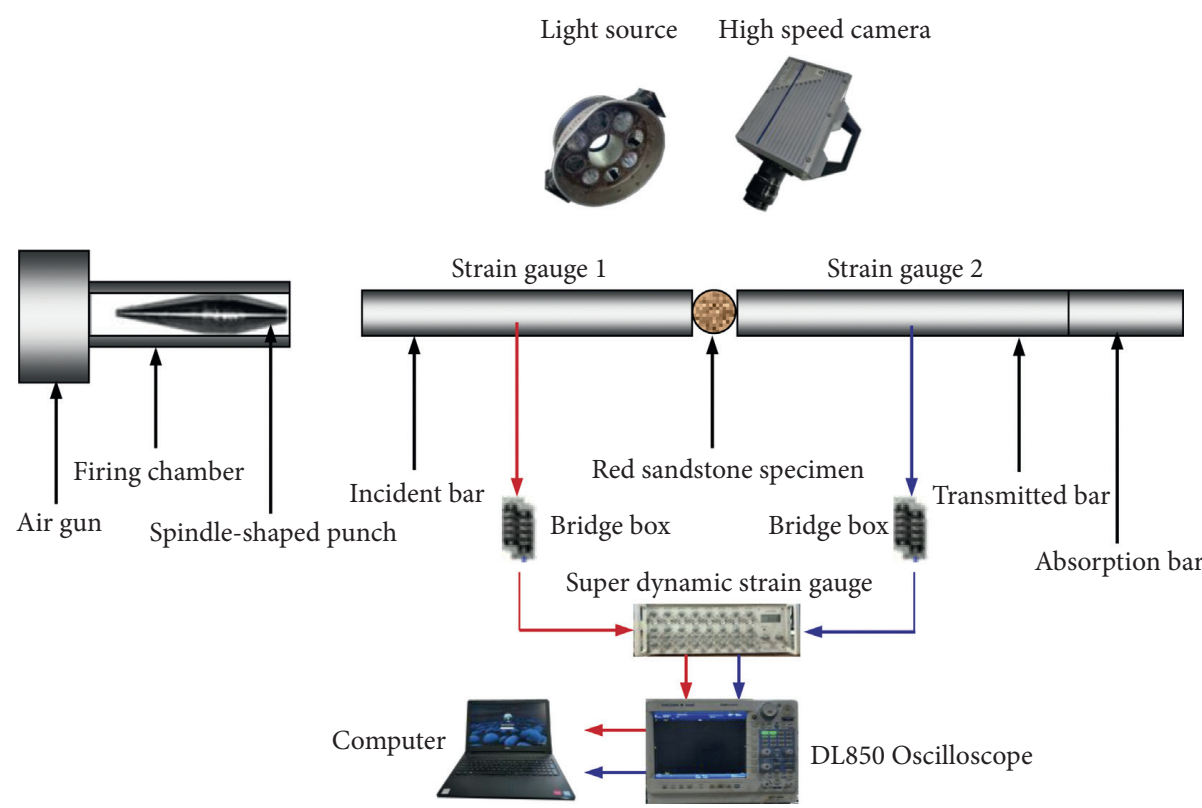

Figure 1: Diagram of the SHPB testing apparatus for the dynamic Brazilian disc tests [22].

wave provides the energy source for the failure of rock specimens. [19-21]. In this study, the dynamic Brazilian disc tests of red sandstone under different incident energies were carried out, and the failure processes of rock specimens were recorded with a high-speed camera. According to the experimental results, the failure modes and energy relationships under different incident energies were analyzed.

\section{Experimental Methods and Materials}

2.1. Test Apparatus. The test was carried out using a conventional SHPB setup [22]. As shown in Figure 1, the test apparatus consisted of three main components: three bars (the incident bar, transmitted bar, and absorption bar), a dynamic load device, and a data acquisition system. The three bars were constructed of $40 \mathrm{Cr}$ alloy steel with a diameter of $50 \mathrm{~mm}$, a density of $7.810 \mathrm{~g} / \mathrm{cm}^{3}$, and a P-wave velocity of $5410 \mathrm{~m} / \mathrm{s}$. The lengths of the incident bar and the transmitted bar were $2.0 \mathrm{~m}$ and $1.5 \mathrm{~m}$. The bullet was a spindle-shaped striker, which could generate a half-sine incident wave to overcome the shortcoming of high-frequency oscillation caused by rectangular waves. The data acquisition system used a super dynamic strain gauge and a DL-850 oscilloscope. The strain gauges were attached to the incident bar and the transmitted bar at a distance of $1.00 \mathrm{~m}$ from the specimen, and the incident strain, reflected strain, and transmitted strain could be measured. The dynamic uniaxial and triaxial compression tests can be conducted on this SHPB device [23].

2.2. Test Principle. According to the principles of dynamic Brazilian disc test and the data collected by the data acquisition system, the tensile stress at the center of the specimen can be calculated by the following formula [22]:

$$
\sigma(t)=\frac{A E}{2 \pi D L}\left[\varepsilon_{I}(t)+\varepsilon_{R}(t)+\varepsilon_{T}(t)\right],
$$

where $A$ and $E$ are the cross-sectional area and Young's modulus of the bar; $D$ and $L$ are the diameter and length of the specimen; $\sigma(t)$ and $\varepsilon(t)$ are the tensile stress and strain of the specimen at moment $t$; and the subscripts $I, R$, and $T$ denote the incident, reflected, and transmitted waves, respectively.

The calculation formulas of the incident energy, reflected energy, and transmitted energy can be expressed as follows:

$$
\begin{aligned}
& E_{I}(t)=E C A \int_{0}^{t} \varepsilon_{I}^{2}(t) \mathrm{d} t, \\
& E_{R}(t)=E C A \int_{0}^{t} \varepsilon_{R}^{2}(t) \mathrm{d} t, \\
& E_{T}(t)=E C A \int_{0}^{t} \varepsilon_{T}^{2}(t) \mathrm{d} t,
\end{aligned}
$$

where $E_{I}(t), E_{R}(t)$, and $E_{T}(t)$ are the cumulative incident energy, reflected energy, and transmitted energy at moment $t$, respectively, and $C$ is the one-dimensional longitudinal stress wave velocity of the bar.

The cumulative dissipated energy at moment $t$ can be calculated from the formula:

$$
E_{D}(t)=E_{I}(t)-E_{R}(t)-E_{T}(t) .
$$

2.3. Specimen Preparation. A block of red sandstone with good integrity and homogeneity was selected for preparing the specimens for the dynamic Brazilian disc tests. According to the suggested method for rock dynamic tests [3], all the specimens were cored from one piece of rock block and processed into cylindrical shapes with a diameter of $50 \mathrm{~mm}$ and a height of $25 \mathrm{~mm}$ (the length to diameter ratio 


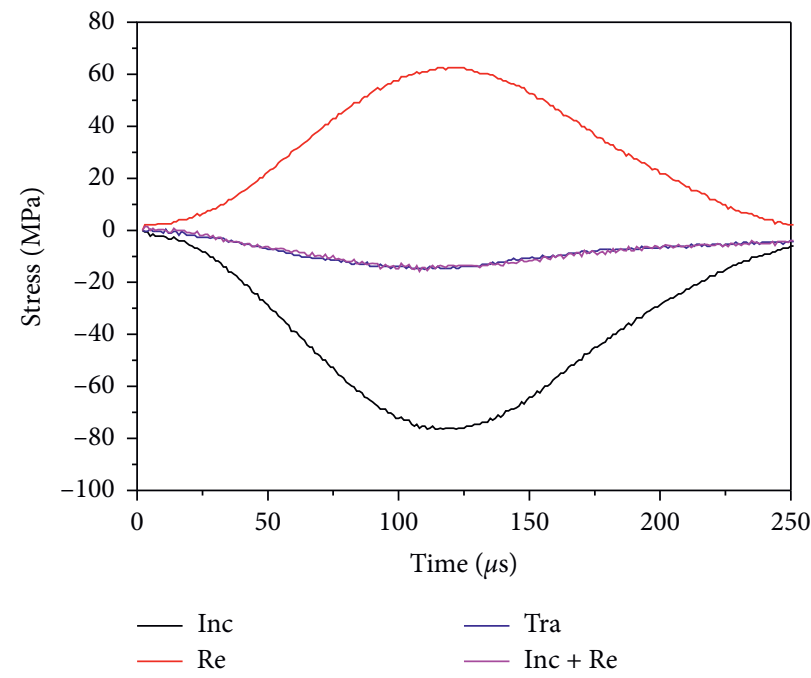

Figure 2: Stress equilibrium check for the dynamic Brazilian disc testing of a red sandstone specimen ('Inc' is the incident stress, 'Re' is the reflected stress, 'Tra' is the transmitted stress, and 'Inc + Re' is the superimposed stress at the end of the incident bar).

TABLE 1: Energy and mechanical data of red sandstone specimens.

\begin{tabular}{|c|c|c|c|c|c|c|c|c|}
\hline $\begin{array}{l}\text { Diameter } \\
(\mathrm{mm})\end{array}$ & $\begin{array}{c}\begin{array}{c}\text { Length } \\
(\mathrm{mm})\end{array} \\
\end{array}$ & $\begin{array}{c}\text { Incident } \\
\text { energy }(\mathrm{J})\end{array}$ & $\begin{array}{l}\text { Dissipated } \\
\text { energy }(\mathrm{J})\end{array}$ & $\begin{array}{l}\text { Reflected } \\
\text { energy }(\mathrm{J})\end{array}$ & $\begin{array}{c}\text { Transmitted } \\
\text { energy }(\mathrm{J})\end{array}$ & $\begin{array}{c}\text { Loading rate } \\
(\mathrm{GPa} / \mathrm{s})\end{array}$ & $\begin{array}{l}\text { Peak tensile } \\
\text { stress }(\mathrm{MPa})\end{array}$ & $\begin{array}{c}\text { States after } \\
\text { impact }\end{array}$ \\
\hline 48.70 & 25.24 & 2.60 & 0.44 & 1.96 & 0.20 & 40.88 & 4.42 & Unruptured \\
\hline 48.65 & 25.44 & 3.66 & 0.90 & 2.57 & 0.18 & 41.99 & 5.12 & Unruptured \\
\hline 48.69 & 25.71 & 4.54 & 0.80 & 3.59 & 0.14 & 38.41 & 4.72 & Unruptured \\
\hline 48.69 & 25.39 & 4.80 & 0.86 & 3.58 & 0.36 & 71.57 & 8.80 & Unruptured \\
\hline 48.70 & 25.14 & 5.96 & 1.46 & 4.24 & 0.26 & 51.56 & 6.29 & Unruptured \\
\hline 48.64 & 24.73 & 6.40 & 1.12 & 4.80 & 0.47 & 57.61 & 7.26 & Ruptured \\
\hline 48.71 & 24.94 & 6.68 & 1.36 & 5.07 & 0.25 & 55.28 & 6.19 & Unruptured \\
\hline 48.69 & 25.56 & 9.01 & 2.31 & 6.01 & 0.69 & 89.82 & 10.96 & Broken \\
\hline 48.75 & 25.61 & 9.02 & 2.35 & 6.21 & 0.45 & 75.77 & 9.62 & Broken \\
\hline 48.71 & 24.55 & 9.10 & 1.87 & 6.74 & 0.49 & 63.83 & 7.98 & Broken \\
\hline 48.70 & 25.81 & 9.78 & 1.89 & 7.51 & 0.38 & 51.51 & 7.37 & Broken \\
\hline 48.67 & 25.81 & 9.43 & 1.92 & 6.73 & 0.77 & 57.77 & 10.05 & Broken \\
\hline 48.67 & 26.15 & 9.68 & 2.24 & 6.81 & 0.63 & 89.91 & 11.24 & Broken \\
\hline 48.64 & 25.84 & 10.16 & 2.38 & 7.04 & 0.74 & 91.07 & 11.20 & Broken \\
\hline 48.70 & 25.54 & 10.43 & 2.80 & 6.97 & 0.67 & 84.54 & 9.81 & Broken \\
\hline 48.73 & 25.41 & 11.06 & 2.43 & 8.13 & 0.50 & 83.98 & 10.33 & Broken \\
\hline 48.71 & 25.79 & 11.64 & 2.81 & 8.56 & 0.28 & 56.36 & 7.95 & Broken \\
\hline 48.67 & 25.36 & 12.10 & 3.64 & 7.92 & 0.54 & 109.37 & 12.69 & Broken \\
\hline 48.65 & 25.52 & 13.25 & 3.98 & 8.49 & 0.79 & 95.46 & 11.74 & Broken \\
\hline 48.66 & 25.43 & 15.04 & 4.12 & 10.42 & 0.50 & 82.78 & 9.93 & Broken \\
\hline 48.70 & 25.69 & 16.67 & 4.68 & 11.39 & 0.60 & 110.22 & 10.58 & Broken \\
\hline 48.65 & 25.96 & 19.75 & 6.15 & 12.86 & 0.75 & 122.92 & 13.40 & Broken \\
\hline 48.70 & 25.49 & 19.84 & 5.88 & 13.27 & 0.70 & 120.87 & 13.66 & Broken \\
\hline 48.70 & 25.73 & 22.90 & 6.97 & 15.34 & 0.60 & 106.19 & 12.96 & Broken \\
\hline 49.68 & 25.29 & 24.55 & 6.97 & 16.98 & 0.60 & 134.88 & 12.95 & Broken \\
\hline 48.69 & 25.64 & 25.05 & 8.37 & 16.00 & 0.68 & 139.52 & 16.05 & Broken \\
\hline 48.66 & 25.52 & 25.63 & 8.32 & 16.66 & 0.65 & 163.10 & 15.82 & Broken \\
\hline 48.64 & 25.89 & 31.75 & 8.81 & 22.28 & 0.66 & 163.33 & 14.05 & Broken \\
\hline
\end{tabular}

was $1: 2$ ). The ends of the specimens were ground by a buffing machine to control the evenness and nonperpendicularity to be less than $0.02 \mathrm{~mm}$. The average density and wave velocity of red sandstone are $2431 \mathrm{~kg} / \mathrm{m}^{3}$ and $3386 \mathrm{~m} / \mathrm{s}$.
2.4. Preparation for Formal Test and Dynamic Equilibrium. Before the tests started, a nonspecimen test was necessary to verify the stability and operability of the SHPB test system. The incident wave should be basically consistent with the transmitted wave during a conventional uniaxial test, which 

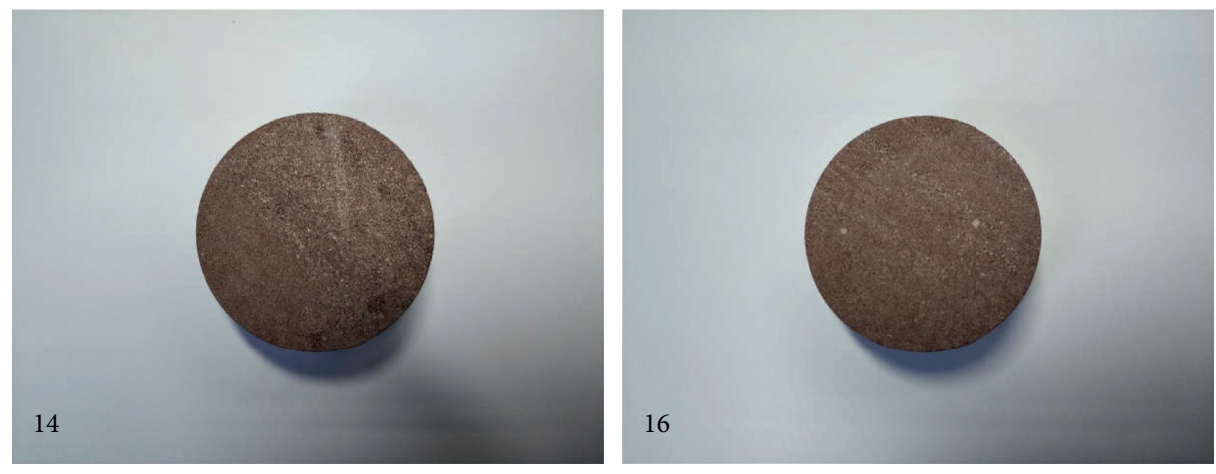

(a)
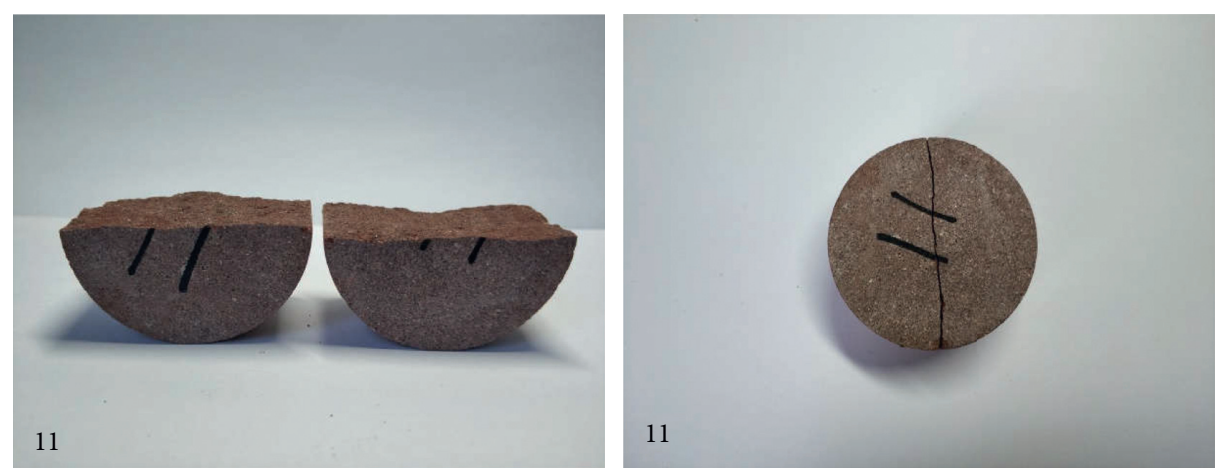

(b)
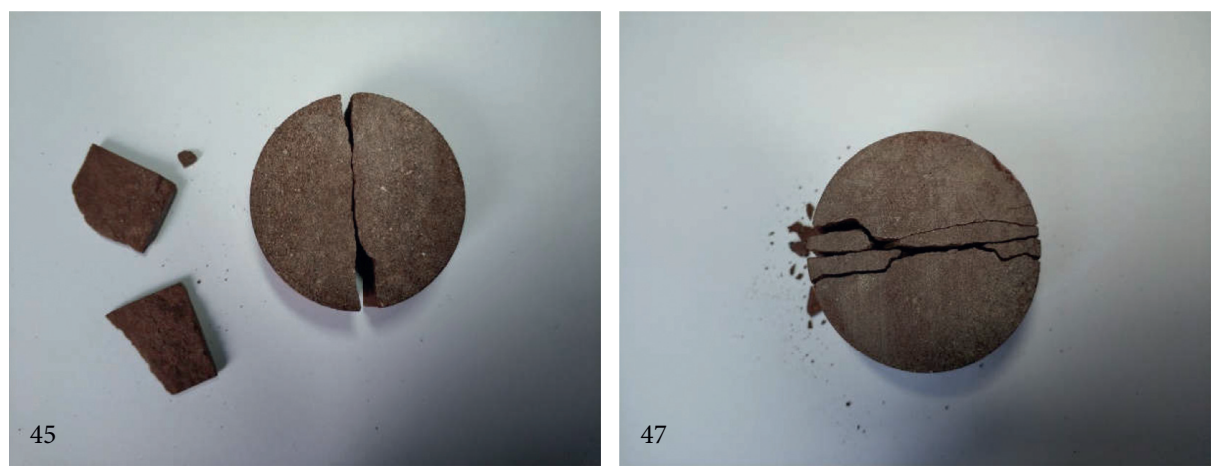

(c)

FIgURE 3: Three failure states of red sandstone specimens after impact: (a) unruptured state; (b) ruptured state; (c) broken state.

indicates that the stability of the test system is up to the standard of formal tests.

The specimen was sandwiched between the incident bar and the transmitted bar in the radial direction, and lubricant was applied at the contact point between the specimen and the two bars to reduce friction. In addition, the validity of the test results should be judged by whether the stress at both ends of the specimen reaches equilibrium before failure.

Figure 2 shows the stress history of a typical dynamic Brazilian disc test in which the ends of the rock specimen reached the equilibrium state. It is observed that the sum of the incident and reflected stress waves 'Inc + Re' is basically consistent with the transmitted stress wave 'Tra'. This denotes that the test results are valid and reliable. Otherwise, the results will be invalid and should be excluded. In this paper, checks of the stress equilibrium were carried out on each of the specimens to ensure the validity and accuracy of the test results.

\section{Results}

The results of dynamic Brazilian disc tests are listed in Table 1. The states of the specimens after impact can be divided into three categories, namely, the unruptured state, the ruptured state, and the broken state. The unruptured state refers to the specimens which remained intact and have the ability to bear a load after impact, as shown in Figure 3(a).

The ruptured state refers to the state in which the specimen produced visible cracks after impact and separated into two blocks, as shown in Figure 3(b). The broken state refers to the state in which the specimen was broken into many rock blocks after impact, as shown in Figure 3(c). It 
can be concluded that there is an incident energy which corresponds to the state of the specimen that changes from the unruptured state to the ruptured state. This incident energy was defined as the critical incident energy. When the incident energy was less than the critical incident energy, the specimens were in the unruptured state after impact, and when the incident energy was greater than the critical incident energy, the specimens were in the broken state after impact.

It can be seen from Table 1 and Figure 3 that when the incident energy was $6.40 \mathrm{~J}$, the specimen was split into two rock blocks along the loading direction. When the incident energy was at a high level and the specimen was broken, there were triangular broken areas at both ends of the specimen. With the augmentation of the incident energy, the degree of broken specimens became higher. This is because before the main radial crack penetrated, the compressive stresses at both ends of the specimen exceeded the tensile strength of the rock.

3.1. Mechanical Properties. Five typical dynamic load-displacement curves are shown in Figure 4; the peak tensile stress of red sandstone specimens under different loading rates is obtained as shown in Table 1. Figure 5 shows the relationship between the peak tensile stress and the loading rate. It can be found that there is an obvious loading rate effect with the peak tensile stress of red sandstone and the logarithmic function can be used to fit this loading effect trend. This rate effect of peak stress has been confirmed in many literature studies $[4,6,7]$ and can be considered as one of the dynamic tensile properties of rock.

3.2. Energy Characteristics. Based on the energy calculation principle of the SHPB dynamic Brazilian disc test, the curves of incident energy, reflected energy, transmitted energy, and dissipated energy relative to time in the dynamic Brazilian disc testing of red sandstone specimens can be calculated. As shown in Figure 6, there are curves of four kinds of energy for specimens 1, 11, and 26 in three states over time. It can be seen that the four kinds of energy all increased with the increase of time and then no longer increased after approximately $250 \mu \mathrm{s}$, after which they remained constant.

3.3. Failure Process of the Specimen. In dynamic loading tests, failure of the specimen is a quickly developing process. To study the failure processes of specimens, effective technical measurements are needed. At present, a high-speed camera is generally used to record the failure processes of specimens. In this study, a high-speed camera was set at 72,000 frames per second (fps) to take a photo every $13.89 \mu$ s. Figures 7(a)7 (c) shows the typical failure processes of red sandstone specimens in the three states after impacting specimens 14 , 11 , and 47. Specimen 14 was in the unruptured state after impact, remaining intact after the impact with no visible cracks on the surface. Specimen 11 was in the ruptures state after the impact. A crack formed on the surface of the specimen at $250.02 \mu \mathrm{s}$, starting at one end of the incident bar and running through the whole specimen along the loading

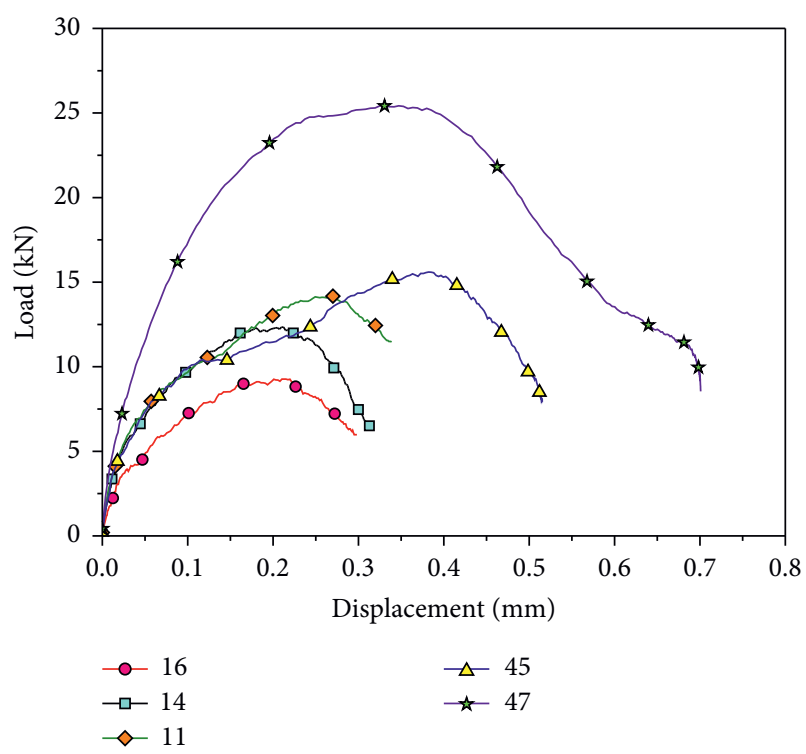

FIGURE 4: Typical dynamic load-displacement curves.

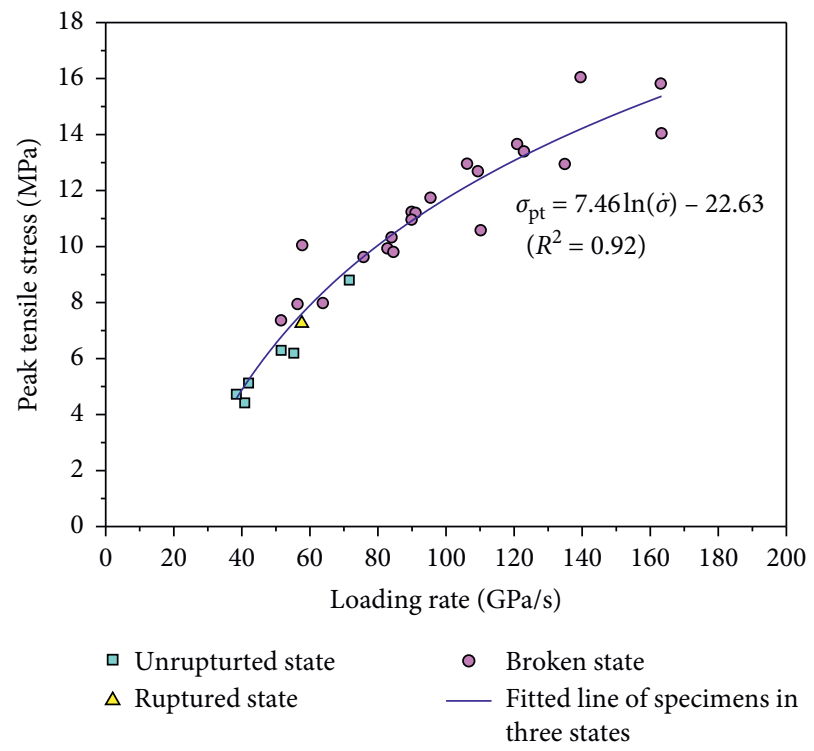

FIGURE 5: Relationship between loading rate and peak tensile stress of red sandstone specimens.

direction. The specimen was separated into two rock blocks at $791.73 \mu \mathrm{s}$. Specimen 47 was broken under a larger dynamic load. The specimen was penetrated by a main crack, and two additional cracks were produced at the contact points between the specimen and the ends of the bars at $250.02 \mu \mathrm{s}$. At $791.73 \mu \mathrm{s}$, the specimen was split into several parts which were flying outward at certain speeds. In addition, the main cracks of specimens 11 and 47 occurred along the direction of the loading stress, which was because the tensile stress of the rock plays a major role in the fracturing of specimens.

3.4. Energy Relationship between the Dissipated Energy and Incident Energy. It can be concluded from Table 1 that the 


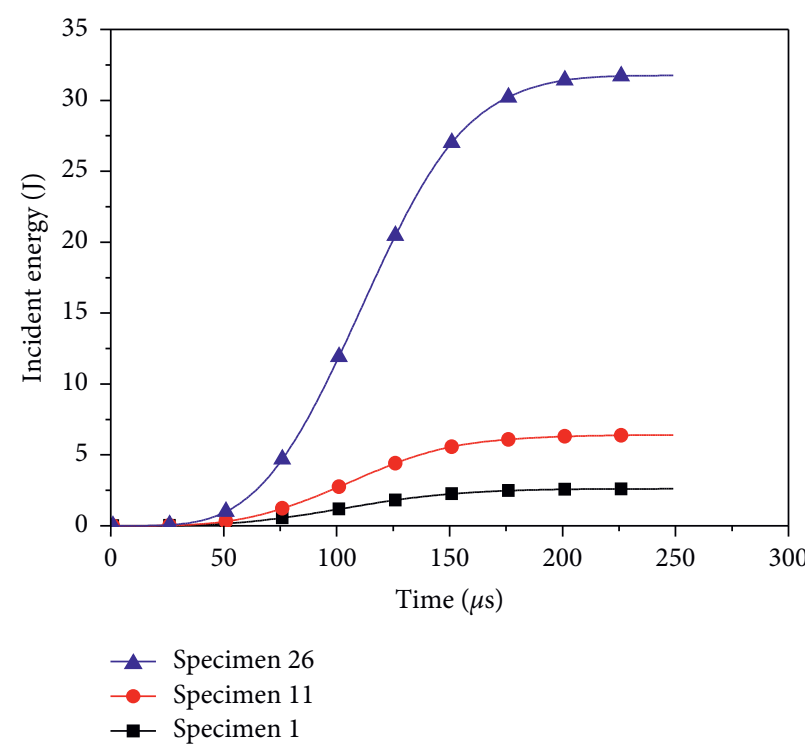

(a)

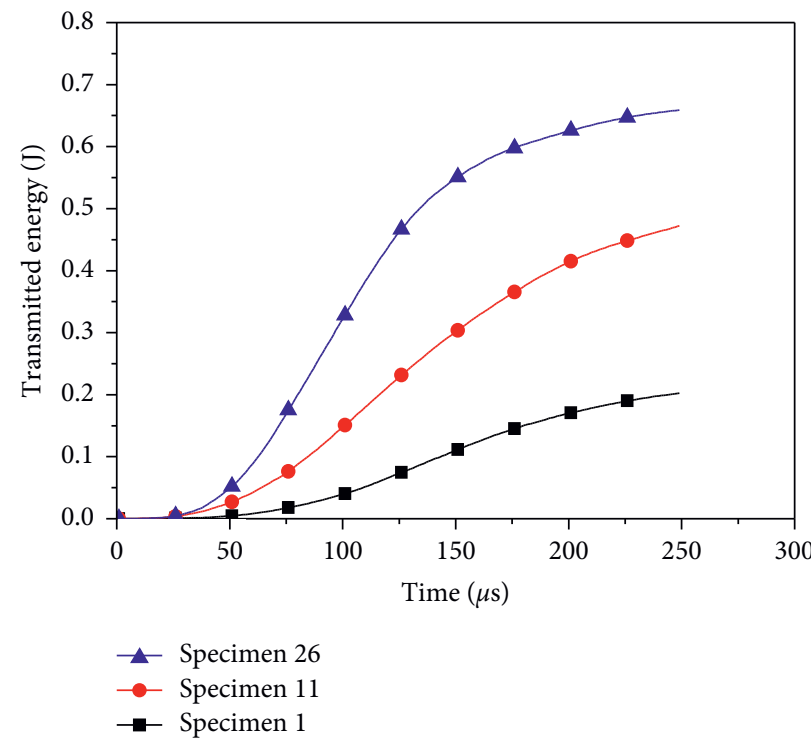

(c)

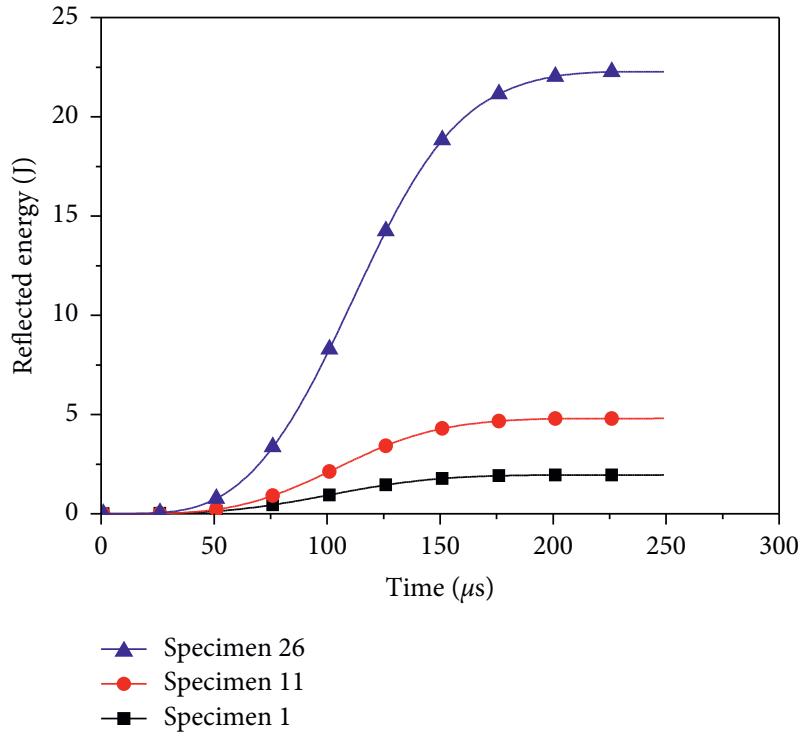

(b)

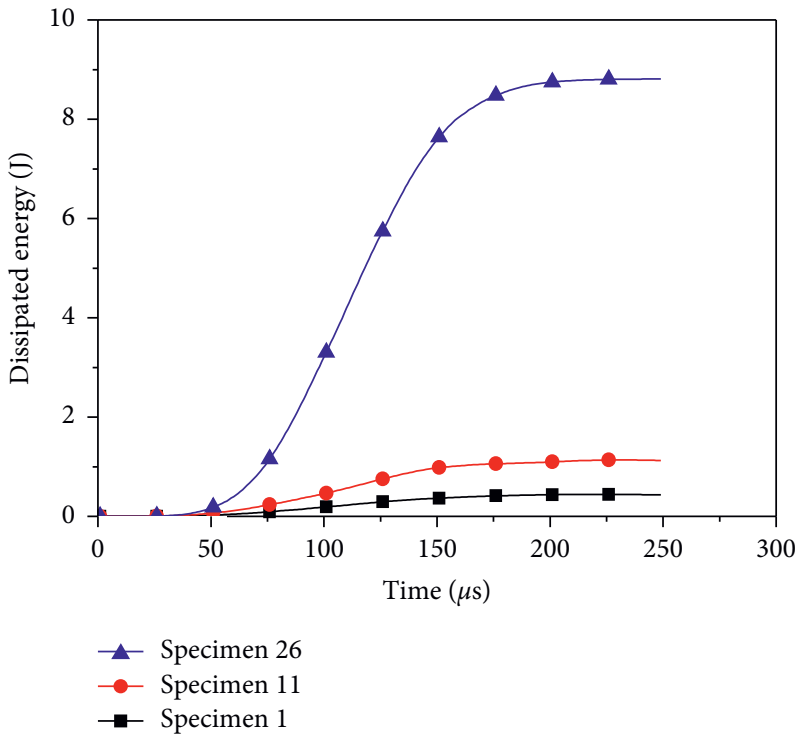

(d)

FiguRe 6: Energy-time curve of red sandstone specimens in the dynamic Brazilian disc test: (a) incident energy-time; (b) reflected energytime; (c) transmitted energy-time; (d) dissipated energy-time.

dissipated energy of the specimens increased with the augmentation of the incident energy, and the states of the red sandstone specimens changed from unruptured state to the ruptured state and then to the broken state.

Figure 8 shows the relationship between the dissipated energy and the incident energy in the dynamic Brazilian disc testing of red sandstone specimens. It can be seen that the dissipated energy increases approximately linearly with the increase of incident energy, and presenting two different stages of energy relationship. From Table 1, it can be found that this feature is related to the state of the specimen after impact, so the linear fitting formulas were used to fit the data points of the unruptured and broken specimens, respectively (to correct the fitting curve of the unruptured state, the origin coordinate was also added, because when the incident energy is $0 \mathrm{~J}$, the dissipated energy must be $0 \mathrm{~J}$ ). The data points for the ruptured state are represented by different shapes than those for the other two states.

The relationships between the dissipated energy and incident energy are both positively linear for the specimens in the unruptured state and broken state after the impact and can be fitted by the following:

$$
\begin{cases}E_{D}^{U}=k_{U} E_{I}+c_{U} & \left(E_{I}<E_{C I}\right) \\ E_{D}^{B}=k_{B} E_{I}+c_{B} & \left(E_{I}>E_{C I}\right)\end{cases}
$$

where $E_{D}^{U}$ and $E_{D}^{B}$ are the dissipated energies of the specimen in the unruptured state and in the broken state, $k_{U}$ and $k_{B}$ are 

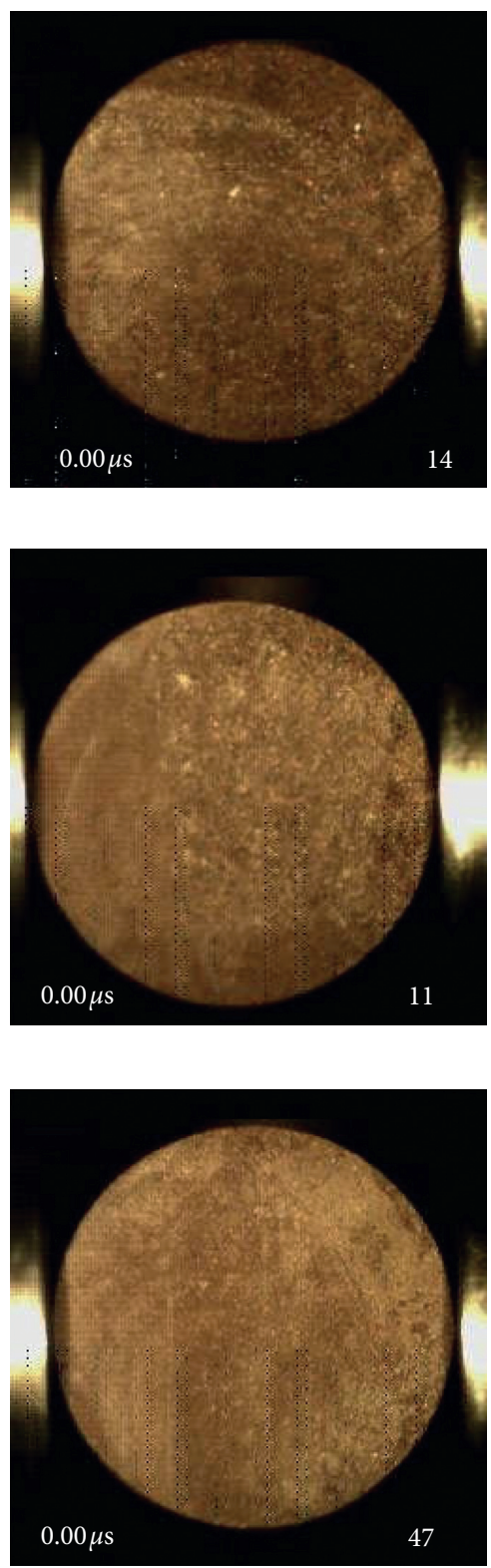

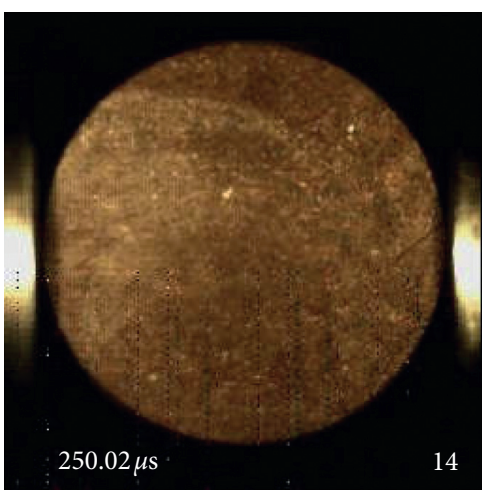

(a)

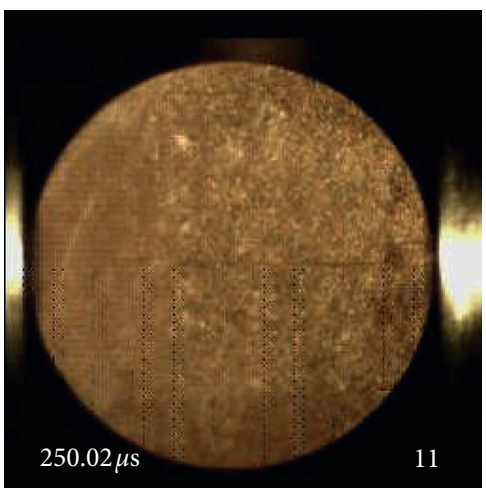

(b)
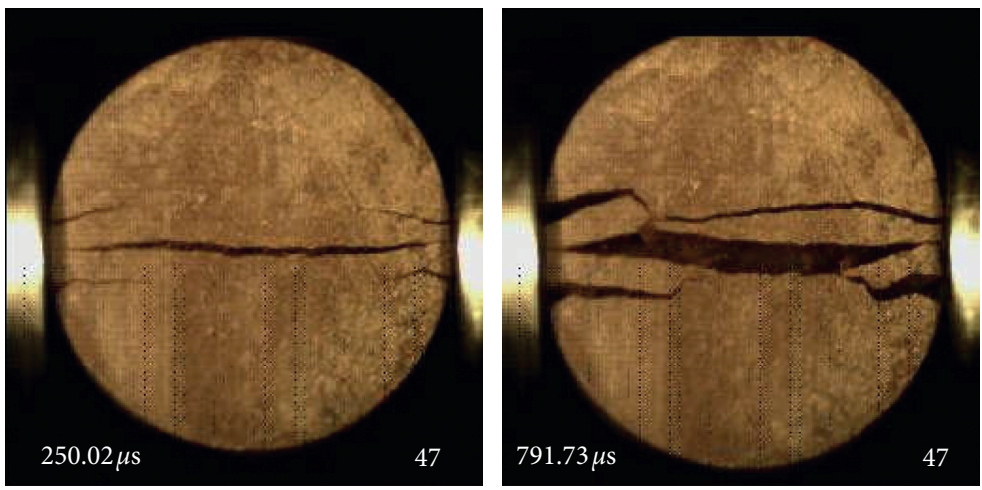
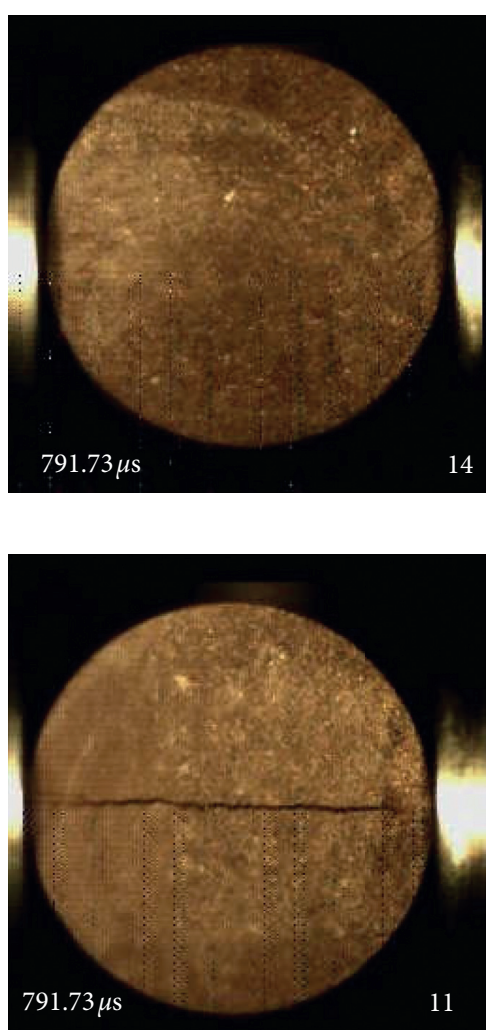

1

(c)

Figure 7: Failure processes of specimens in three states: (a) unruptured state; (b) ruptured state; (c) broken state.

the slopes of the fitted curves of the unruptured state and broken state, $E_{I}$ is the incident energy, $c_{U}$ and $c_{B}$ are constants of the unruptured state and broken state, and $E_{C I}$ is the critical incident energy, which corresponds to the ruptured state of the specimen after impact. For the red sandstone in this study, two fitting functions can be obtained as follows:

$$
\begin{cases}\frac{E_{D}^{U}}{E_{I}}=0.22-\frac{0.04}{E_{I}}, & \left(E_{I}<7.5 J\right), \\ \frac{E_{D}^{B}}{E_{I}}=0.34-\frac{0.94}{E_{I}}, & \left(E_{I}>7.5 J\right) .\end{cases}
$$




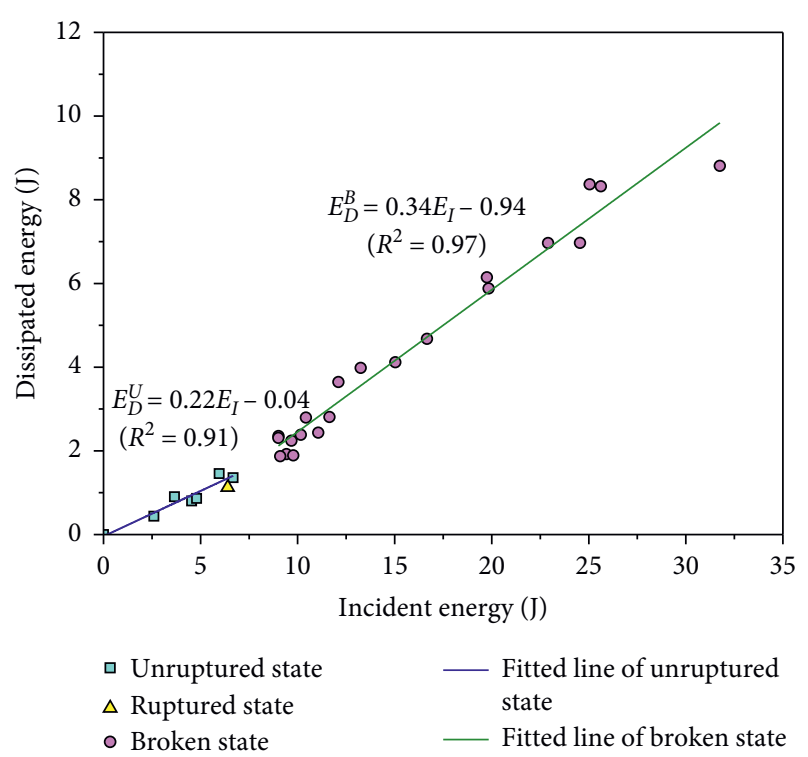

FIgURE 8: Fitted lines of the dissipated energy-incident energy in the " $U$ " state and " $B$ " state (" $U$ " state is the unruptured state and " $B$ " state is the broken state).

$$
\begin{cases}\frac{E_{D}^{U}}{E_{I}}=0.22, & \left(E_{I}<7.5 J\right), \\ \frac{E_{D}^{B}}{E_{I}}=0.34-\frac{0.94}{E_{I}}, & \left(E_{I}>7.5 J\right) .\end{cases}
$$

The ideal curve obtained according to formula (6) was shown in red line in Figure 9. The DTEDC of the specimen in the unruptured state after impact is 0.22 . When the incident energy exceeds $7.5 \mathrm{~J}$, the state of the specimen after impact will develop from a ruptured state to a broken state, and the DTEDC begins to increase. It can be seen from Figure 9 that the DTEDC increases with the increase of incident energy, and the velocity decreases gradually. The same conclusion can be drawn from formula (6), and the DTEDC will gradually increase and approach to 0.34 .

\section{Discussions}

4.1. Loading Rate Effect. As shown in Figure 5, there is no obvious difference among these three failure states. Therefore, from the relationship between the peak tensile stress and loading rate, it is impossible to distinguish the difference in mechanical properties of the failure state of the specimen. However, from the point of view of energy, as mentioned above, we find that there are two stages of linear energy dissipation between these states.

4.2. Failure State. It can be seen from Figure 7 that, when the specimen is in the ruptured state, that is, specimen 11, there is only one main crack that penetrates the whole specimen, with the specimen divided into two parts along the crack. It

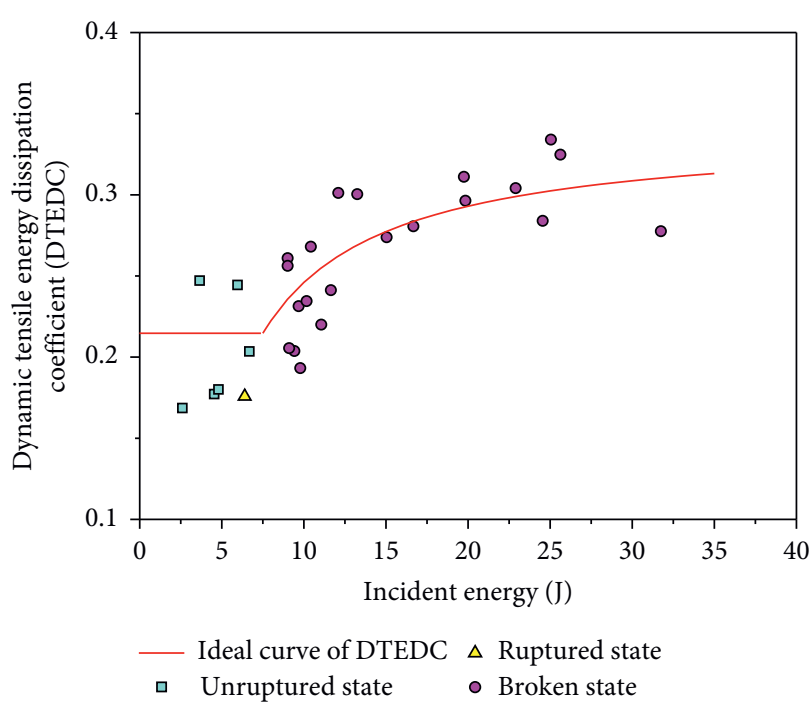

FIGURE 9: Relation of incident energy versus DTEDC.

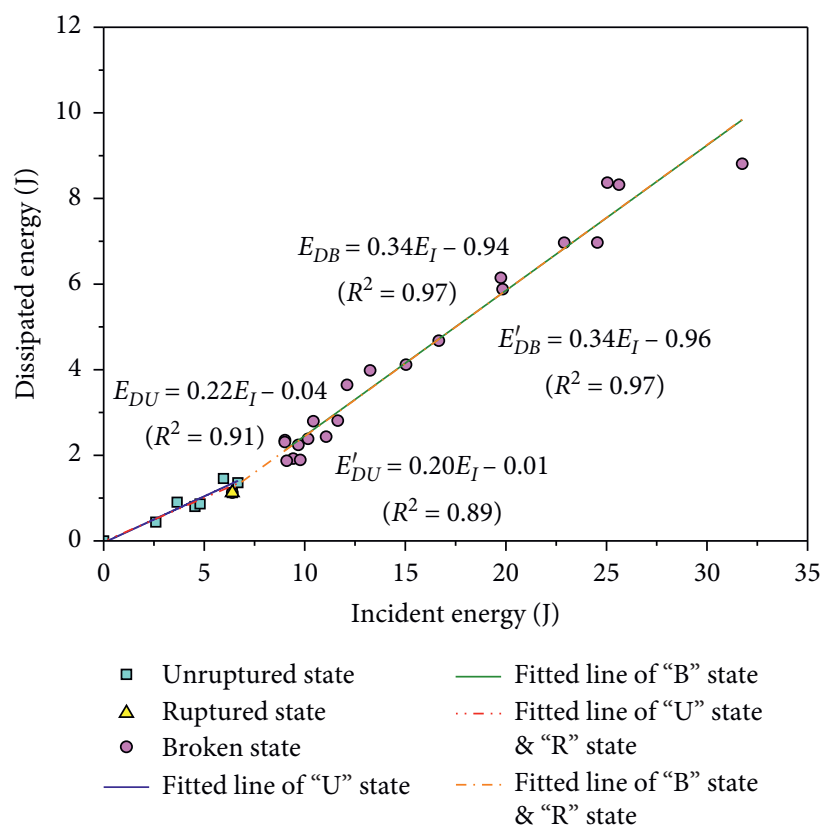

Figure 10: Fitted lines of the incident energy-dissipated energy in the " $U$ " state, " $B$ " state, " $U$ " state \& " $R$ " state, and " $B$ " state \& " $R$ " state (" $U$ " state is the unruptured state, " $B$ " state is the broken state, and " $R$ " state is the ruptured state).

is noteworthy that this specimen produced not only microcracks propagation but also macrocracks penetration, and the specimen is at the critical point at which the kinetic energy of the rock fragments is about to be generated.

The data of the ruptured specimen 11 has been fitted together with those from the unruptured and broken states specimens to create fitting lines, and the two previous fitting lines were retained for comparison, as shown in Figure 10. The two previous fitting lines and the other two 
fitting lines including the critical-state specimen are listed as follows:

$$
\begin{aligned}
& \left\{\begin{array}{l}
E_{D U}=0.22 E_{I}-0.04, \\
E_{D U^{\prime}}=0.20 E_{I}-0.01,
\end{array}\right. \\
& \left\{\begin{array}{l}
E_{D B}=0.34 E_{I}-0.94, \\
E_{D B^{\prime}}=0.34 E_{I}-0.96 .
\end{array}\right.
\end{aligned}
$$

It can be seen that the two fitted lines after adding the specimen in the ruptured state almost coincide with the previous fitted lines, so the data of the specimen in the ruptured state can be fitted with the data of other unruptured and broken specimens. As shown in Figure 10, the specimen data point in the ruptured state is approximately at the intersection of the two fitted lines.

In addition, for the dynamic Brazilian disc test, because of the relatively small dynamic tensile stress, it is difficult to obtain the specimen of the critical state, so there is only one critical-state specimen in this paper.

\section{Conclusions}

In this paper, a series of dynamic Brazilian disc tests of red sandstone specimens were carried out using the SHPB setup. The main conclusions can be described as follows:

(1) In the dynamic Brazilian disc test, the rock specimen has three states after impact with different incident energy: the unruptured state, ruptured state, and broken state. And the ruptured state is corresponding to the critical energy. When the incident energy is less than the critical energy, the specimen remains intact and there is no macrocrack on the surface, that is, the unruptured state; when the incident energy is greater than the critical energy, the specimen will be damaged and lose the bearing capacity along the loading direction, that is, the broken state.

(2) Under the impact of different incident energy, the dynamic peak stress and loading rate of red sandstone specimens show a unified exponential function relationship. However, the failure states of specimens after impact cannot be identified from this relationship.

(3) There are linear relationships between the dissipated energy and incident energy in both the unruptured state and the broken state. In the broken state, the dissipated energy increases with the increase of incident energy, and the increasing speed is faster than that of the unruptured specimen.

(4) According to the loading process recorded with a high-speed camera, the failure mode of the specimen is splitting along the loading direction. When the specimen is in the critical failure mode after the impact, only one crack is produced along the loading direction, and it penetrates the whole specimen, so that the specimen is divided into two parts. When the specimen is in the broken state, except the main crack along the loading direction, additional cracks will be generated at both ends of the specimen connecting the incident and transmission reinforcement, and these cracks will also expand along the loading direction.

(5) When the specimen is in the unruptured state after impact, the ideal DTEDC is a constant value, which is 0.22 for the red sandstone specimen in this paper. However, when the specimen is in a broken state after impact, the DTEDC increases with the increase of incident energy and gradually approaches 0.34 .

\section{Data Availability}

No data were used to support this study.

\section{Conflicts of Interest}

The authors declare that they have no conflicts of interest.

\section{Acknowledgments}

This study was supported by the National Natural Science Foundation of China (Grant no. 41877272).

\section{References}

[1] ISRM, "Suggested methods for determining tensile strength of rock materials," International Journal of Rock Mechanics \& Mining Sciences, vol. 15, no. 1, pp. 881-891, 1978.

[2] ASTM D3967-08, Standard Test Method for Splitting Tensile Strength of Intact Rock Core Specimens, ASTM International, West Conshohocken, PA, USA, 2008.

[3] Y. X. Zhou, K. Xia, X. B. Li et al., "Suggested methods for determining the dynamic strength parameters and mode-I fracture toughness of rock materials," International Journal of Rock Mechanics and Mining Sciences, vol. 49, pp. 105-112, 2012.

[4] F. Q. Gong, L. Zhang, and S. Y. Wang, "Loading rate effect of rock material with the direct tensile and three Brazilian disc tests," Advances in Civil Engineering, vol. 2019, Article ID 6260351, 8 pages, 2019.

[5] F. Q. Gong, X. B. Li, and J. Zhao, "Analytical algorithm to estimate tensile modulus in Brazilian disk splitting tests," Chinese Journal of Rock Mechanics and Engineering, vol. 29, no. 5, pp. 881-891, 2010.

[6] F. Q. Gong and G. F. Zhao, "Dynamic indirect tensile strength of sandstone under different loading rates," Rock Mechanics and Rock Engineering, vol. 47, no. 6, pp. 2271-2278, 2014.

[7] Q. B. Zhang and J. Zhao, "A review of dynamic experimental techniques and mechanical behaviour of rock materials," Rock Mechanics and Rock Engineering, vol. 47, no. 4, pp. 1411-1478, 2014.

[8] J. B. Zhu, Z. Y. Liao, and C. A. Tang, "Numerical SHPB tests of rocks under combined static and dynamic loading conditions with application to dynamic behavior of rocks under in situ stresses," Rock Mechanics and Rock Engineering, vol. 49, no. 10, pp. 3935-3946, 2016.

[9] J. C. Li, L. F. Rong, H. B. Li, and S. N. Hong, "An SHPB test study on stress wave energy attenuation in jointed rock masses," Rock Mechanics and Rock Engineering, vol. 52, no. 2, pp. 403-420, 2019. 
[10] D. Asprone, E. Cadoni, A. Prota, and G. Manfredi, "Dynamic behavior of a Mediterranean natural stone under tensile loading," International Journal of Rock Mechanics and Mining Sciences, vol. 46, no. 3, pp. 514-520, 2009.

[11] Q. Z. Wang, W. Li, and H. P. Xie, "Dynamic split tensile test of flattened Brazilian disc of rock with SHPB setup," Mechanics of Materials, vol. 41, no. 3, pp. 252-260, 2009.

[12] E. Cadoni, "Dynamic characterization of orthogneiss rock subjected to intermediate and high strain rates in tension," Rock Mechanics and Rock Engineering, vol. 43, no. 6, pp. 667-676, 2010.

[13] F. Dai and K. Xia, "Loading rate dependence of tensile strength anisotropy of Barre granite," Pure and Applied Geophysics, vol. 167, no. 11, pp. 1419-1432, 2010.

[14] B. Wu, W. Yao, and K. Xia, "An experimental study of dynamic tensile failure of rocks subjected to hydrostatic confinement," Rock Mechanics and Rock Engineering, vol. 49, no. 10, pp. 3855-3864, 2016.

[15] H. Xie, L. Li, R. Peng, and Y. Ju, "Energy analysis and criteria for structural failure of rocks," Journal of Rock Mechanics and Geotechnical Engineering, vol. 1, no. 1, pp. 11-20, 2009.

[16] F. Q. Gong, S. Luo, and J. Y. Yan, "Energy storage and dissipation evolution process and characteristics of marble in three tension-type failure tests," Rock Mechanics and Rock Engineering, vol. 51, no. 11, pp. 3613-3624, 2018.

[17] F. Q. Gong, J. Y. Yan, S. Luo, and X. B. Li, "Investigation on the linear energy storage and dissipation laws of rock materials under uniaxial compression," Rock Mechanics and Rock Engineering, vol. 52, no. 11, pp. 4237-4255, 2019.

[18] Y. Chu, H. Sun, and D. Zhang, "Experimental study on evolution in the characteristics of permeability, deformation, and energy of coal containing gas under triaxial cyclic loading-unloading," Energy Science \& Engineering, vol. 7, no. 5, pp. 2112-2123, 2019.

[19] B. Lundberg, "A split Hopkinson bar study of energy absorption in dynamic rock fragmentation," International Journal of Rock Mechanics and Mining Sciences \& Geomechanics Abstracts, vol. 13, no. 6, pp. 187-197, 1976.

[20] A. V. Mikhalyuk and V. V. Zakharov, "Dissipation of dynamic-loading energy in quasi-elastic deformation processes in rocks," Journal of Applied Mechanics and Technical Physics, vol. 38, no. 2, pp. 312-318, 1997.

[21] X. B. Li, T. S. Lok, and J. Zhao, "Dynamic characteristics of granite subjected to intermediate loading rate," Rock Mechanics and Rock Engineering, vol. 38, no. 1, pp. 21-39, 2005.

[22] F. Q. Gong, Experimental study of rock mechanical properties under coupled static-dynamic loads and dynamic strength criterion, Ph.D. thesis, Central South University, Changsha, China, 2010.

[23] F. Q. Gong, X. F. Si, X. B. Li, and S. Y. Wang, "Dynamic triaxial compression tests on sandstone at high strain rates and low confining pressures with split Hopkinson pressure bar," International Journal of Rock Mechanics and Mining Sciences, vol. 113, pp. 211-219, 2019. 